\title{
Guided Bone Regeneration and Simultaneous Implant Placement
}

\author{
Stefan Peev ${ }^{1}$, Angela Gusiyska ${ }^{2}$, Elitsa Sabeva ${ }^{1}$ \\ ${ }^{1}$ Department of Periodontology and Dental Implantology, Medical University of Varna, Bulgaria \\ ${ }^{2}$ Department of Conservative Dentistry, Medical University of Sofia, Bulgaria
}

\begin{abstract}
This study included 954 implants placed simultaneously with guided bone regeneration. The method was performed in cases with horizontal and vertical deficit (up to $3 \mathrm{~mm}$ ) of the alveolar bone, measured by cone-beam computed tomography. We used pericardial collagen barrier membraneand the following bone grafting materials - BoneCeramic ( Institut Straumann - Basel, Switzerland), Cerabone ( Botiss, Berlin, Germany) and Maxresorb Inject (Botiss, Berlin, Germany). The patients were monitored for 2 to 5 years. The survival rate was 99,5\%, as 5 of 954 implants failed. The mean marginal bone loss is 0,094mm.
\end{abstract}

Keywords: Guided Bone Regeneration, Dental Implants

\section{Introduction}

One of the most commonly used methods in regard to the implant treatment in the cases of alveolar bone deficit is the guided bone regeneration. The aim of this study is to establish the mean marginal bone loss and the survival rate of the implants placed simultaneously with guided bone regeneration, the distribution of the method according to the areas, where it was performed and according to the type of the alveolar bone atrophy. Also the aim was to confirm the effectiveness of the method to provide a volume stability and soft tissue aesthetics.

\section{Literature Survey}

Nyman (1) defines the guided tissue regeneration as a principle, that is based on the hypothesis that non-desirable types of tissue cells can be prevented from migrating into a wound by means of barrier membrane and at the same time giving preference to those particular cells to repopulate the wound, which have the capacity to regenerate the desired type of tissue. Soon after the presentation of the principle of guided regeneration was proved the fact, that the periosteum can't serve as a barrier membrane. On the contrary - the periosteum is a source of fast-growing fibrous connective tissue that fills the main volume of the coated with periosteum defect $(2,3)$. For the first time the term "guided bone regeneration" is used by Buser et al. $(4,5)$ in a series of articles describing the use of method in regeneration of bone defects in upper and lower jaw. It is important to preserve a sufficient volume under the barrier membrane, which is required for the regeneration. Otherwise, the results regarding to the recovered bone volume are poor (6). The use of bone grafting materials in combination with barrier membrane was described by Seibert and Nyman (7). Compared to the bone grafting materials, the barrier membrane is more important in regard to the bone regeneration. Gotfredsen et al. (8) observed the outcomes of regeneration using barrier membrane; barrier membrane in combination with hydroxyapatite and hydroxyapatite without a barrier membrane. Using histological analysis it was established, that the best results were obtained by using barrier membrane in combination with hydroxyapatite and the most unsatisfactory results were obtained by using hydroxyapatite without a membrane. The results of using barrier membrane alone are similar to those of the combination of membrane and hydroxyapatite.

\section{Methods}

This study included 954 implants placed simultaneously with guided bone regeneration. The method was performed in the cases with horizontal and vertical deficit (up to $3 \mathrm{~mm}$ ) of the alveolar bone, which was measured using cone-beam computed tomography.

In the relevant edentulous area was elevated muco-periosteal flap using one horizontal incision along the alveolar crest and one or two paramedian vertical incisions. After the implant placement the muco-periosteal flap was mobilized by cutting the periosteum apical to the mucogingival junction. Pericardial collagen barrier membrane (Jason Membrane - Botiss, Berlin, Germany ) and bone grafting material were used. We used Bone Ceramic (Institut Straumann - Basel, Switzerland), Cerabone (Botiss, Berlin, Germany) and Maxresorb Inject (Botiss, Berlin, Germany). The flap was repositioned and sutured using a 5/0 monofilament polyamide thread (Dafilon, B.BraunMelsungen, Germany) with single interrupted sutures. A second-stage surgery was performed after the third month after the implant placement. The primary stability was measured before the implants were functionally loaded. The primary stability was assessed using the dumping capacity measured with Periotest device (Gulden Medizintechnic Germany). The results were registered as periotest values(PTV), as implants with PTV from -08 to 0 were considered successful integrated and implants with PTV 1 and more were considered unsuccessful. In the control visit the following were registered: presence of early postoperative complications, marginal bone resorption visible on radiography, as as reference was used the implant length, the survival rate of the implants, placed simultaneously with guided bone regeneration for the observation period and presence or absence of bleeding on probing(BOP). The BOP was performed with a periodontal probe UNC-15. 


\section{International Journal of Science and Research (IJSR) \\ ISSN (Online): 2319-7064 \\ Index Copernicus Value (2013): 6.14 | Impact Factor (2014): 5.611}

\section{Results}

The patients were monitored for 2 to 5 years.. The mean age of the patients was 37,34 years. The survival rate was $99,5 \%$, as 5 implants failed from 954 implants placed simultaneously with guided bone regeneration. The mean marginal bone loss is $0,094 \mathrm{~mm}$. This is due to the fact, that in $89,1 \%$ of the cases no bone loss, visible on radiography was observed. In the cases of registered bone loss was established, that the mean bone loss increased proportional to the increasing observation period. Bleeding on probing was registered in $9 \%$ of the cases. In the cases with observed bleeding on probing the mean marginal bone loss was $0,907 \mathrm{~mm}$ and in the cases without registered bleeding on probing the mean marginal bone loss was $0,013 \mathrm{~mm}$. Bone resorption is observed only in 19 cases without established bleeding on probing and in 104 cases with registered bleeding on probing. This correlation supports the hypothesis, that the main reason for the marginal bone loss is related to the inflammation of the peri-implant tissues. In $7,4 \%$ of the cases was observed dehiscence of the barrier membrane. There were observed no complications requiring special treatment. No other early postoperative complications were observed. No correlation was established between the bone grafting material and the bone loss, neither between the type of the treated bone deficit and the bone loss.

\section{Discussion}

The analysis of the results shows high survival rate of the implants placed simultaneously with guided bone regeneration. The grate number of the implants included in the study confirms the significance and the representativeness of the obtained results. They are similar to those, which Chiapasco et al. (9), Fugazzotto et al. (10) and Juodzbalys et al. (11) report. The mean marginal bone loss is extremely low- $0,094 \mathrm{~mm}$. Bone resorption is registered in a small number of the cases in a low values. These facts support our view, that the bone grafting materials, that we used-biphasic calcium phosphate ceramic with high porosity $(90 \%)$ and synthetic biphasic nanohydroxyapatite paste in combination with pericardial collagen membrane demonstrate complete recovery of the bone defects and excellent volume stability over the time. Therefore, our study confirms the thesis that the method is useful for providing long-lasting volume stability - resp. soft tissue aesthetics in the aesthetic area.

\section{Conclusion}

The guided bone regeneration with simultaneous implant placement is a method with high survival rate and high predictability. When guided bone regeneration with simultaneous implant placement is performed using a synthetic biphasic calcium phosphate material with a high porosity, sintered deproteinized bovine bone mineral and synthetic biphasic nano-hydroxyapatite paste in combination with pericardial collagen membrane, the bone defect completely regenerate, as the newly formed tissues demonstrate high volume stability. Guided bone regeneration in combination with the observed bone grafting materials is a proper method to provide long-lasting volume stability and soft tissue aesthetics.

\section{References}

[1] Nyman S.,Bone regeneration using the principle of guided tissue regeneration.J Clin Periodontol. 1991 Jul;18(6):494-8.

[2] Dahlin C., Linde A, Gottlow J, Nyman S.,Healing of bone defects by guided tissue regeneration.,Plast Reconstr Surg. 1988 May;81(5):672-6.

[3] Dahlin C., Sandberg E, Alberius P, Linde A.Restoration of mandibular nonunion bone defects. An experimental study in rats using an osteopromotive membrane method.Int J Oral Maxillofac Surg. 1994 Aug;23(4):237-42.

[4] Buser D., Dula K, Belser UC, Hirt HP, Berthold H.Localized ridge augmentation using guided bone regeneration. 1. Surgical procedure in the maxilla. Int J Periodontics Restorative Dent. 1993;13(1):29-45.

[5] Buser D., Dula K, Belser UC, Hirt HP, Berthold H.Localized ridge augmentation using guided bone regeneration. II. Surgical procedure in the mandible.Int J Periodontics Restorative Dent. 1995 Feb;15(1):10-29.

[6] Buser D., Bragger, U., Lang, N.P. \& Nyman, S. Regeneration and enlargement of jaw bone using guided tissue regeneration. Clinical Oral Implants Research 1990,1: 22-32.

[7] Seibert J, Nyman S., Localized ridge augmentation in dogs: a pilot study using membranes and hydroxyapatite. J Periodontol. 1990 Mar;61(3):157-65.

[8] Gotfredsen, K., Warrer, K., Hjorting Hansen, E. Karring, T. Effect of membranes and porous hydroxyapatite on healing in bone defects around titanium den tal implants. An experimental study in monkeys. Clinical Oral Implants Research 2 : 172-178. (1991)

[9] Chiapasco M, Abati S, Romeo E,Vogel G. Clinical outcome of autogenous bone blocks or guided bone regeneration with e-PTFE membranes for the reconstruction of narrow edentulous ridges. Clin Oral Implants Res 1999; 10:278-288.

[10]Fugazzotto PA. Success and failure rates of osseointegrated implants in function in regenerated bone for 6 to 51 months. Int J Oral Maxillofac Implants 1997;12:17-24.

[11] Juodzbalys G, Raustia AM, Kubilius R. A 5-year follow-up study on one-stage implants inserted concomitantly with localized alveolar ridge augmentation. J Oral Rehabil 2007;34:781-789.

\section{Author Profile}

Stefan Peev DMD, PhD, DSc - Professor (Associate), Head of Department of Periodontology and Dental Implantology, Medical University of Varna, Bulgaria, Director of University Dental Clinic - Varna

Angela Gusiyska, DMD,PhD - Assistant Professor - Department of Conservative Dentistry, Medical University of Sofia, Bulgaria

Elitsa Sabeva DMD - Assistant Professor at Department of Periodontology and Dental Implantology, Medical University of Varna, Bulgaria 